\title{
A MUNDIALIZAÇÃO DA EDUCAÇÃO: NEOLIBERALISMO E SOCIAL-DEMOCRACIA NO BRASIL E NA VENEZUELA
}

\author{
THE GLOBALIZATION OF EDUCATION: NEOLIBERALISM AND SOCIAL DEMOCRACY IN \\ BRAZIL AND VENEZUELA
}

Adriana Almeida Sales de Melo 1

Resumo O presente texto tem como objetivo ap resentar características do processo de mundialização da educação, considerado um dos elementos de uma nova fase de internacionalização e acumulação capitalistas conduzida hegemonica mente pelos sujeitos políticos coletivos que assumem o projeto neoliberal de sociabilidade - especialmente o Fundo Monetário Internacional (FMI) e o Banco Mundial (BM), condutores das re formas estruturais para a América Latina e o Caribe - definindo as conseqüências da consolidação deste projeto para a redefinição das políticas educacionais na região, especificamente no Brasil e na Venezuela, a partir da década de 1980.

Palav ras chave educação-Brasil; educação-Ven ezuela; política educacional; mundialização.
Abstract This article intends to introduce a few characteristics of the process of globalization of education, considered one of the elements of the new phase of capitalist internationalization and accumulation which has been put through hegemonically by collective political actors that adopted the neoliberal project of sociability (especially the International Monetary Fund (IMF) and the World Bank, the conductors of structural reforms in Latin America and the Caribbean). The article also describes the consequences of this project's implementation on educational policies of the region, specifically Brazil and Venezuela, from the 80's until now.

Key words education-Brazil; education-Venezuela; educational policies; globalization. 


\section{Introdução}

Agradecendo o convite da revista Trabalho, Educação e Saúde, gostaria de propor para debate o tema mundialização da educação a partir da investigação realizada, inicialmente, em tese de doutoramento defendida em 2003, na Faculdade de Educação da Universidade Estadual de Campinas, e publicada no ano seguinte sob o título $A$ mundialização da educação: consolidação do projeto neoliberal na América Latina - Brasil e Venezuela (Melo, 2004).

No Brasil, entre as décadas de 1980 e 1990, vivenciamos momentos de conquistas democráticas e socialização da participação política. A classe trabalhadora, após 21 longos anos de ditadura militar, começava nova mente a sentir a possibilidade de realização de suas demandas por bem-estar social e também a se mobilizar e reorganizar para construir e fortalecer seu projeto de sociabilidade.

O entusiasmo pela democracia tão esperada e duramente negociada fazia com que, na época, todas as críticas parecessem simplesmente pessimismo. No entanto, mesmo em nosso país já não podíamos mais negar os efeitos n e fastos das políticas de ajustes e suas condicionalidades de empréstimos, conduzidas pelo capitalismo internacional, representado por duas de suas ma i o resagências financiadoras: o Fundo Monetário Internacional (FMI) e o Banco Mundial (BM). A interferência dos chamados países desenvolvidos na condução da relação entre Estado e mercado nos países em desenvolvimento constituiu-se, desde o período pós-guerras mundiais, em uma tensão fundamental para a compreensão do processo de mundialização do capital no fim do século XX.

Enfim, só na década de 1990 pudemos compreender claramente que liberalismo e neoliberalismo têm premissas dife rentes quando se trata do desenvolvimento de países ricos e de países pobres.

No entanto, a dupla contradição encontrada nas sociedades capitalistas contemporâneas, apontada por Coutinho (2000), entre a socialização da participação política e a ap ropriação privada do poder, concomitante à socialização do trabalho e à ap ropriação privada dos seus frutos, realiza-se de maneira diferenciada em cada formação social concreta.

Foi em busca desta especificidade que, em 1992, começamos a investigar o planejamento e as mudanças político-educacionais na cidade de Recife, Pernambuco. Cito este exemplo porque, em 1993, quando ainda não apareciam com muita clareza na produção científica do Brasil questionamentos sobre os rumos da mundialização do capital, em Recife já presenciá vamos a realização das Conferências Municipais da Educação - para a formulação de um Plano Decenal - que mostravam claramente, na composição das mesas de debate, grupos de trabalho e plenárias, a presença de novos sujeitos políticos coletivos em confronto. Estes eram tanto clara e assumidamente 
conservadores quanto revolucionários na intenção de realizar projetos distintos de sociabilidade e educação (Melo, 1998).

Desde aquela época, nos perguntávamos como o projeto de sociabilidade neoliberal chegara tão longe a ponto de alcançar não só as grandes cidades e suas regiões metropolitanas como também os rincões do nosso país, encontrando-se em nossas fronteiras com o mesmo mov i mento vindo de vizinhos igualmente atingidos pelo que, na época, se vangloriava com o epíteto de 'pensamento único'. Quais as estratégias de formação de consenso (Neves, no prelo)?

Neste debate, nos propomos a ap resentar algumas das principais características da mundialização do capital e como a mundialização da educação se realizou no processo de condução de um novo bloco histórico no mundo.

\section{Características da mundialização na década de 1980}

A concentração cada vez mais intensa do capital nos países desenvolvidos centrais, calcada na descentralização da produção, provocou umap rofu ndamento das condições de exploração do trabalho e o aumento do desemprego, como forma de manter crescentes as taxas de lucro dos empréstimos e investimentos do capital privado internacional. A 'refuncionalização' do Estado realizou-se tanto no sentido de uma maior racionalização e eficiência estrutural quanto no da redução do gasto social público. Tanto significou a privatização de empresas e órgãos públicos estatais quanto a desre sponsabilização do Estado em relação às atividades relativas ao bem-estar social, inclusive em suas funções essenciais de saúde e educação. Este movimento resultou na precarização da qualidade de vida nesses países, com o aumento da pobreza e da miséria.

O processo de 'aceitação e implantação' do movimento de 'ajuste, por meio de reformas, para o crescimento', dirigido principalmente pelo FMI e BM, para a América Latina e o Caribe, teve como direção central - como continuidade das agendas de liberalização do comércio, desregulamentação e privatização - a reforma do Estado, que se realizou de formas dife renciadas de acordo com a correlação de forças sociais presentes em nossos países. Este processo também significou uma mudança de rumo ideológico no próprio sentido da internacionalização capitalista dirigido aos países em desenvolvimento, dando uma nova dimensão à relação entre E stado e sociedade.

Uma das preocupações que aparece de forma sistemática nos discursos daquelas agências diz respeito às prováveis reações da população contra as re formas e a conseqüente tomada de posição das dive rsas frações das classes dominantes locais, pois, apesar de incentiva rem a democratização como forma de legitimar as re formas do estado, envolvendo as demandas da po- 
pulação e os processos de liberalização, desregulamentação e privatização, estas reformas apresentam cunho anti-social.

$\mathrm{Na}$ defesa do capitalismo, o neoliberalismo como projeto de sociabilidade assume novas formas, embora mantenha suas premissas liberais fundamentais. A preocupação com uma 'governança progressiva' se expande na década de 1990, principalmente entre os países em que partidos e frentes 'de esquerda' assumem um projeto de 'reforma' e 'humanização' do capitalismo.

\section{Políticas sociais entre as novas funções do Estado na década de 1990}

No final do século passado, os organismos internacionais que defendem e implementam o processo histórico contraditório e excludente de mundialização do capital (conduzido desde a década de 1970 pelo FMI e BM para os países em desenvolvimento) tenderam a atribuir novos valores à ação dos países, dos Estados-nações, re forçando sua dimensão soberana, mas apenas como instância responsável tanto por seu próprio sucesso neste processo de mundialização do capital quanto por manter funções básicas de segurança, regulamentação do trabalho, conservação da propriedade privada, saúde e educação.

Entre as 'novas funções do Estado', preconizadas especialmente pelo BM, estaria a recuperação desta soberania, com ênfase nos seus processos de 'governação'. Isto é, a capacidade de dirigir, administrar e induzir demandas econômicas e sociais, que estaria diluída entre vários sujeitos sociais que não fariam parte exclusivamente do governo - seriam as organizações não-governamentais e agências transnacionais. Em outras palavras, orga n izações sociais restritas e não necessariamente representativas, locais e internacionais estariam assumindo o caráter de instância de resolução dos conflitos sociais.

A governação é a proposta estratégica de conformação ético-política da 'nova social-democracia' — a social-democracia da 'terceira via' —, assumida como discurso pelas instâncias que conduzem mundialmente o projeto neoliberal em defesa do capital, re presentando as condições de continu idade das reformas neoliberais, que têm se consolidado nos países da América Latina e do Caribe a partir da década de 1980.

\footnotetext{
“Uma nova relação entre o Estado em seu sentido restrito e a socied ade é gestada para este fim. Na linguagem do Banco Mundial (BM), desde os anos 90, novas funções do Estado são necessárias para conduzir um mundo em transformação. Um novo bloco histórico conservador em defesa do capital é gestado. Os organismos internacionais lançam mão de novas estratégias de ação tanto na condução da política econômica quanto da conformação social dos países. As novas funções do Estado envolvem desde a gestão das pequenas re formas para implantar as grandes
} 
reformas (BM, 1997), até a formulação de uma nova conformação social. O Estado aparece para os países 'pobres' nova mente como gestor de compensações. Mínimo mas capaz de garantir a execução de uma nova forma de relacionamento social e também de garantir a ordem social, preoc upação constante tanto mais se agr avam as conseqüências das re formas com relação ao empobre ci mento dos países" (Melo, no prelo, p. 84, grifos do autor).

As principais características desta nova fase de acumulação capitalista incluem: a) incorporação do conhecimento como força produtiva principal do modo de produção social, processo que se consolida de forma concentrada nos países desenvolvidos, incluindo os acordos de cooperação tecnológica, que acabam aumentando o grau de marginalização dos países subdesenvo lvidos; b) fortalecimento do capital privado e enfraquecimento da esfera pública, como movi mento de reprodução ampliada do capital, ap rofundando a dependência econômica entre os países; c) desemprego e mudanças nas necessidades de qualificação para o trabalho, associados ao desmonte das políticas sociais, como movimento de reprodução ampliada do trabalho; d) intensificação das políticas de 'formação de consenso', associadas à captação de recursos e às políticas de empréstimo de agências financeiras internacionais, estabelecendo novas condicionalidades na formulação de políticas para as regiões e os países.

\section{A mundialização da educação}

A partir da década de 1980, as políticas educacionais também seguiram estes movi mentos de mundialização do capital. Proclamada como área fundamental a ser desenvolvida nas ações para a redução da pobreza nas regiões subdesenvolvidas, a educação também sofre mudanças no FMI e BM, tanto no sentido da uniformização dos empréstimos e condicionalidades, quanto do a u mento da importância dada à eficiência e à eficácia dos projetos e progr amas na área.

Conduzida principalmente pelo FMI e pelo BM, associados à Organização das Nações Unidas para a Educação, Ciência e Cultura (Unesco), é construída uma agenda de formulação e realização de políticas educacionais para a América Latina e o Caribe. Lançada de forma mais ampla na Conferência Mundial de Educação para Todos, realizada em Jomtien, na Tailândia, em 1991, essa agenda logrou incorporar demandas construídas décadas a fio por educadores e setores das classes populares de diversos países. Pela primeira vez em toda a história um movimento tão abrangente reuniu esforços conjuntos para traçar eixos comuns de ação no campo educacional: a universalização da educação, a gestão democrática da educação e a valorização e pro- 
fissionalização do magistério; eixos também voltados especialmente para demandas específicas de populações mais pobres, educação de meninas e mulheres e etnias marginalizadas do processo de integração ao capitalismo.

Centrada no Programa de Educação para Todos, essa agenda provocou uma uniformização das políticas educacionais em nossa região, tendo sido implantada paulatinamente e concomitantemente nos países latino-americanos.

Do ponto de vista das agências de empréstimos internacionais, a educação torna-se o eixo principal das políticas de redução da pobreza, associada à vocação dos países subdesenvolvidos para o consumo de ciência e tecnologia: uma combinação de arg u mentos que resulta numa condução políticoeducacional que privilegia o investimento na educação que prepara para o trabalho simples (Neves, 2002), voltada principalmente para a população entre sete e 14 anos (cada país tem uma faixa etária e uma denominação dife rente para o ensino fundamental regular). No entanto, verificou-se nos países latino-americanos que, malgrado a focalização das políticas para o ensino fundamental regular - excluindo paulatinamente programas para a educação de zero a seis anos e de 15 a 18 anos, bem como as ações de educação de jovens e adultos e demais modalidades - também o ensino de sete a 14 anos teve restrições de financiamento (Melo, 2004). Além dessa diminu ição, a focalização em determinado nível da educação escolar provoca sérios danos na passagem de crianças e adolescentes para o nível posterior. Em nossos países, é muito utilizada para ilustrar essa restrição, desde a década de 1970, a imagem do gargalo de garrafa e do funil para expressar a disparidade estatística entre alunos que entram no sistema da educação escolar pública e os que conseguem terminar ou passar de um nível para outro.

Estes direcionamentos acabaram por causar danos nefastos à direção das políticas educacionais dos países da América Latina e Caribe, diminuindo os investimentos na educação pública, bem como contribuindo para a fragmentação e o desmonte dos sistemas educacionais da região.

O Programa de Educação para Todos, desde seu planejamento inicial, foi um programa amplo de redirecionamento e condução político-educacional para a América Latina e o Caribe, de caráter restritivo e profundamente excludente, tendo também contribuído para estimular a privatização competitiva no campo educacional, restringindo e seccionando os vários níveis de ensino.

Em alguns países, como a Argentina, pesquisadores debruçam-se corajosamente sobre problemasrelativos à 'redução da aprendizagem' entre níveis da educação e também entre gerações, causados por esse desmonte dos sistemas nacionais de educação. No Brasil, no entanto, o Ministério da Educação afirma que a educação escolar fundamental regular está universalizada, faltando apenas se imprimir uma maior 'qualidade social' à educação, no sentido também de responsabilizar dire ta mente as escolas, os trabalhadores da educação envolvidos e 'toda a sociedade'. 
Foi principalmente na década de 1990 que se realizaram, no contexto de redirecionamento das reformas neoliberais dirigidas aos países em desenvolvimento, em especial para a América Latina e o Caribe, as mudanças político-educacionais, no contexto da mundialização do capital, no Brasil e na Venezuela, conduzidas principalmente pelo BM e pela Unesco, nos movimentos de implantação do Programa de Educação para Todos nestes países.

A despeito das profundas diferenças históricas nacionais, o Educação para Todos se implantou como um programa hegemônico de homogeneização e redirecionamento de políticas educacionais para a América Latina e o Caribe.

A escolha do Brasil e da Venezuela para a investigação de formações sociais concretas, onde este processo de reformas políticas educacionais se realizou - como elemento do projeto neoliberal de sociedade e de educação - , fundamentou-se especialmente nas suas diferenças históricas nacionais. Estes dois países passaram por formas distintas de aprofundamento da ocidentalização, entre as décadas de 1980 e 1990, e, no entanto, a agenda de continuidade e homogeneização das re formas político-educacionais da Unesco e do BM foi mantida e realizada.

\section{A mundialização da educação no Brasil}

No Brasil, a mundialização da educação mantém características históricas fundamentais de exclusão social, mantendo o dualismo entre a educação para as massas e para as elites, organizando os sistemas educacionais para capacitação e geração de conhecimentos diferenciados. Para os que realizam ou realizarão o trabalho simples, direciona

“(...) seus componentes curriculares e sua estrutura organizacional para aumentar o patamar mínimo de escolarização. Esse patamar se traduz na aquisição de conteúdos mínimos de natureza científico-tecnológica e de normas de conduta que capacitem essa parcela da força de trabalho a operar com produtividade as novas máquinas e adaptar-se aos novos requerimentos de sociabilidade da nova organização do trabalho e da produção inerentes ao paradigma da automação flexível, bem como acatar, como alternativa universalmente válida, a lógica neoliberal de organização societal" (Neves, 1999, p. 135).

Por outro lado, quando voltado para os que realizarão o trabalho completo, o sistema

“(...) redireciona suas atividades curriculares e a estrutura organizacional de nível superior para capacitar essa parcela da força de trabalho a adaptar produtivamen- 
te a ciência e a tecnologia transferidas ao país pelos grandes grupos transnacionais e, ao mesmo tempo, oferecer à sociedade homens capazes de organizar a nova cultura empresarial, seja na própria empresa, no cotidiano, na sociedade civil e, também, na aparelhagem governamental" (Neves, 1999, p. 135).

No Brasil, o projeto neoliberal começou a ser implementado em 1990, e foi redirecionado a partir de 1995, numa condução social-democrata presente até os dias de hoje. O processo de 'refuncionalização do Estado', implantado desde aquele ano, deu início a um novo dimensionamento das esferas pública e privada no país.

A conformação das políticas educacionais brasileiras ao processo de mu ndialização da educação envolveu sérios conflitos entre o Ministério da Educação e Cultura (MEC) - associado aos seus principais parceiros, como o Conselho Nacional de Secretários da Educação (Consed), a União Nacional de Dirigentes Municipais da Educação (Undime) e a Confederação Nacional dos Trabalhadores em Educação (CNTE), principalmente na década de 1990 e a sociedade civil, organizada em torno do Fórum em Defesa da Escola Pública e mobilizada nos Congressos Nacionais de Educação.

A partir do reconhecimento do intenso processo de ocidentalização, com o aumento da complexidade e frag mentação da sociedade brasileira, esses sujeitos políticos coletivos envolvidos na realização da agenda do Programa de Educação para Todos promoveram um extenso rol de discussão e divulga ção, envolvendo uma multiplicidade de ações coletivas locais e nacionais, que aconteceram de forma concomitante em diversos estados e municípios do país, com o objetivo de legitimar as sugestões do Plano Decenal de Educação para Todos (1993) do MEC. A Semana Nacional de Educação para Todos (1993) lançou o Compromisso Nacional de Educação para Todos e a Conferência Nacional de Educação para Todos (1994), o Acordo Nacional de Educação para Todos, num processo de consolidação da agenda internacional de reformas econômicas, políticas e sociais para o nosso país (Melo, 2004).

Os resultados da implantação da agenda neoliberal no campo educacional foram sentidos no Brasil ainda na década de 1990: o corte sistemático de gastos para as áreas sociais, entre outros, contribuiu para consolidar a posição de dependência associada do nosso país em relação ao capitalismo internacional.

Lúcia Neves (1999) propõe alguns eixos para a discussão das conseqüências desta política para a educação no Brasil. Um primeiro ponto seria o desmonte do arcabouço normativo da estrutura e do financiamento do sistema educacional brasileiro, modificando propostas presentes na Lei de Diretrizes e Bases da Educação (LDB) de 1996 e apoiadas pelos setores populares, como a criação do Conselho Nacional de Educação (CNE) como um órgão do governo (lei $\mathrm{n}^{\circ}$ 9.131/95) e não como instância representativa e de participação social. 


\begin{abstract}
“Entre outras ações, a criação do Fundo de Manutenção e Desenvolvi mento do Ensino Fundamental e de Valorização do Magistério (Fundef) contribuiu para aprofundar o processo de impedimento e restrição do acesso das camadas popula resà educação, focalizando o investimento no ensino fundamental regular (de sete a 14 anos), inviabilizando a ampliação e mesmo a manutenção do investimento dos municípios e estados na educação infantil (de zero a seis anos), na educação média (de 15 a 18 anos) e no ensino básico supletivo de jovens e adultos; deixando de fora do sistema educacional público nacional, de forma cada vez mais intensa, a população de 15 anos ou mais que não completou sua educação básica na idade correspondente. Com o Fundef, também foi perdida momentaneamente a batalha pelo piso salarial único para os trab al ha d o res da educação (previsto anteriormente também pelo próprio Acordo Nacional), com a instituição de um valor per capita nacional único" (Melo, 2004, p. 218).
\end{abstract}

Um segundo ponto seriam as mudanças no contexto curricular, com a uniformização dos Parâmetros Curriculares Nacionais para a educação básica como mais um elemento de formação de consenso. Outras mudanças estão relacionadas às formas de gestão do sistema educacional e da escola, sendo que cada vez mais o MEC ap rofunda sua estratégia de centralização de decisões e descentralização de ações em relação às políticas educacionais em nosso país.

Estes embates expressaram a direção e o ritmo que tomaram as políticas educacionais no Brasil da década de 1990, no conflito entre o projeto neoliberal de sociedade e de educação — desde esta década com uma face social-democrata na defesa do Programa de Educação para Todos - e o projeto democrático de massas, na defesa da educação pública de qualidade para todos, e para todos os níveis.

\title{
A mundialização da educação na Venezuela
}

A Venezuela enfrentou o processo de implantação do neoliberalismo uma década antes do Brasil. A crise financeira do início da década de 1980 foi um dos elementos que levou à formação da Comissão para a Reforma do Estado (Copre) já em 1984, instituindo o processo de re forma do Estado cujos lemas principais eram a retomada do crescimento e o aprofundamento das instâncias democráticas.

A partir de 1989, com o presidente Carlos Andrés Perez assumindo a política de ajuste econômico do FMI, tem início o processo de consolidação do projeto neoliberal na Venezuela. No entanto, os efeitos nefastos das reformas econômicas e sociais não tardaram a apa recer, causando empobre cimento da população e impedindo a atuação dos canais de participação polí- 
tica das classes populares, que terminaram por interromper o processo de consolidação do projeto neoliberal com a destituição do presidente. A forte resistência da população, porém, não impediu que, no período de 1994 a 1998, esse projeto fosse renovado com a eleição de Rafael Caldera, que deu prosseguimento às políticas de ajustes e reformas do FMI e BM.

A agenda do Programa de Educação para Todos seguiu as recomendações do IX Plano da Nação (1995-1999), em que a educação segue como eixo central das ações pela redução da pobreza, processo apoiado pelo Minist e r i o de la Educación, Cultura y Deportes (Mined), pela Igreja e pelos empresários leigos de ensino. Num diagnóstico sobre os programas de ajustes e reformas realizados entre as décadas de 1980 e 1990, o IX Plano esclarece que, "no que diz respeito à educação, a última década tem sido cenário de fenômenos de reve rsão da qualidade nos níveis de educação básica e média, de ir relevância das aprendizagens, de incrementos na evasão de estudantes e de redução das oportunidades de acesso à educação" (Mined, apud Melo, 2004, p. 245).

No entanto, apesar da clareza da relação entre empobrecimento e exclusão educacional, ambos causados pelas reformas, o próprio documento estabelece a necessidade de uma 'inserção competitiva internacional' para superar os níveis de pobreza da época, embora não tenha apontado nenhum caminho ou forma de investimento para tal, salvo o próprio BM.

Também nessa época diversos sujeitos políticos coletivos se articularam, realizando ações propositivas contra o projeto neoliberal de sociedade e de educação, na defesa da educação pública para todos em todos os níveis, e da instituição do 'estado docente' como um estado social de direitos sociais, com o CNE e a Federação Venezuelana de Mestres.

\section{Considerações finais}

A mundialização do capital, como uma nova fase no processo de internacionalização do capital, ap rofunda e consolida, de novas maneiras, a desigualdade social, a superexploração do trabalho, as práticas de extermínio e a exclusão social tanto entre classes sociais quanto entre países e regiões de nosso planeta. O discurso da globalização como forma integrada e harmoniosa de desenvolvimento e crescimento capitalista, associado à realização do projeto neoliberal de sociedade e de educação, conduziu o processo excludente da mundialização do capital desde a década de 1980.

No entanto, este processo de mundialização da educação, que pressupõe vocações produtivasregionais, realiza-se de forma concomitante, mas profundamente dife renciada, em cada país, enfrentando a resistência de diversos sujeitos políticos coletivos. 
O processo de mundialização da educação, como parte do processo de mundialização do capital, tem efeitos restritivos e seletivos nas políticas educacionais dos países da América Latina e Caribe.

Por um lado, tivemos grandes ganhos na década de 1990, como a implantação de ações com maior continuidade - planejadas para ultrapassar a dimensão das gestões governamentais em seus diversos níveis - e a ex igência de maior eficiência e eficácia, incluindo a ampliação da discussão sobre a necessidade da avaliação contínua das políticas educacionais. Houve ainda uma ampliação da participação popular nas decisões e realizações das políticas educacionais, fruto também de intensa resistência da sociedade civil organizada, tornando mais expressiva a participação de diversos sujeitos políticos coletivos.

Por outro lado, esta uniformização em que se fundamentam as reformas educacionais conduzidas pelo FMI, BM e Unesco provocou o desmonte dos sistemas educacionais locais, restringindo e redirecionando as nossas políticas educacionais para a educação fundamental pública regular, bem como estimulando a privatização da educação como um serviço e não como um direito social.

Assim como o projeto neoliberal não ap resenta uniformidade, mas um pluralismo de tendências ao qual devemos estar atentos (Coutinho, 2000), também o projeto democrático de massas representa uma grande diversidade de sujeitos políticos coletivos com propostas educacionais diferenciadas. Contribuir para a construção deste projeto democrático de massas significa também priorizar a análise histórica de nossas formações sociais concretas.

\section{Nota}

1 Pro fessora do Centro de Educação e Vice-Coordenadora do Mestrado em Educação Brasileira da Universidade Federal de Alagoas. Doutora em Educação pela Universidade Estadual de Campinas.<adriana.melo@cedu.ufal.br> 


\section{Referências}

BANCO MUNDIAL. 1997. Relatório sobre o desenvolvimento mundial: o Estado num mundo em transformação. Washington: Banco Mundial.

COUTINHO, Carlos Nelson. 2000. Contra a corrente:ensaios sobre democracia e socialismo. São Paulo: Cortez.

MELO, Adriana A. S. de. 1998. Educação e hegemonia no Brasil de hoje. Maceió: Edufal. 2004. A mundialização da educação: consolidação do projeto neoliberal na América Latina (Brasil e Venezuela). Maceió: Edufal.

. (no prelo). Os organismos internacionais na condução de um novo bloco histórico. In: NEVES, Lúcia Maria W. (org.). A pedagogia da hegemonia: estratégias da burguesia brasileira para educar o consenso na atualidade. São Paulo: Xamã.

NEVES, Lúcia Maria W. 1999. Educação: um caminhar para o mesmo lugar. In: LES BAUPIN, Ivo (org.). O desmonte da nação: balanço do governo FHC. Petrópolis: Vozes, p. 133-152.

2002. Brasil ano 2000: uma nova divisão do trabalho na educação. $2^{\mathrm{a}}$ ed. São Paulo: Cortez.

NEVES, Lúcia Maria W. (org.). (no prelo). A pedagogia da hegemonia: estratégias da b u rguesia brasileira para educar o consenso na atualidade. São Paulo: Xamã. 